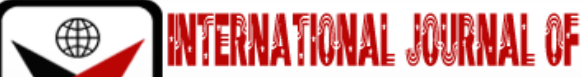

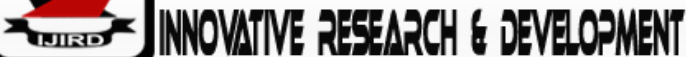

ISSN 2278-0211 (Online)

\section{Evaluation of the Wind Energy Potential in the North-Eastern Part of Nigeria, West Africa: Case Study Gombe State, Nigeria}

Wilfred, Manliura Amthombata
Ph.D. Student, Department of Physics,
Modibbo Adama University of Technology Yola, Adamawa State, Nigeria
Yusufu, Joshua Lanipi
Senior Lecturer, Department of Physics Education,
Federal College of Education (Technical), Gombe, Gombe State, Nigeria

\begin{abstract}
:
Energy is one of the essential requirements for the existence of human race, it is required to sustain and improved the standard of life. Wind energy resources are considered among the fastest growing energy resources all over the world, it offers numerous advantages including clean fuel source that do not produce atmospheric pollutants that causes acid rain and greenhouse gases. It is one of the lowest - priced atmospheric renewable energy technologies. This project focused on evaluation of the wind energy potential in the North - Eastern part of Nigeria West Africa. In achieving this statistical method of research analysis were employed - regression and correlation, percentage distribution and graphical method for data analysis. It was found that the average measured wind power, wind speed and temperature difference between maximum and minimum values for the period (2007 to 2010) occurred in May, June, and July and November and December respectively. The effective percentage of the annual power density of $46.24 \%$ gave up to $50.03 \% \mathrm{~W} / \mathrm{M}^{2}$ power density which is sufficient to serve as power supply in the North - Eastern region of Nigeria. This will play important role in the energy policy of Nigeria since it has the ability to save power and it can be operated either alternatively or in parallel with diesel engine to reduce fuel consumption.
\end{abstract}

Keywords: Turbine, speed, power, generator, and machine

\section{Introduction}

\subsection{Background}

Energy is one of essential requirement for the existence of human race, this energy manifests itself in many forms for instance heat, light, electricity, radiation and matter. Energy is required to sustains and improve the standard of life.

Wind energy is the kinetic energy that is present in moving air; the amount of potential energy depends mainly on wind speed, but is also affected slightly by the density of the air, which is determined by the air temperature, barometric pressure and altitude. For any wind turbine, the power and energy output increase dramatically as the wind speed increase. Therefore, the most cost-effective wind turbine is located in the windiest areas wind speed is affected by the local terrain and increase with height above the ground, so wind turbine is usually mounted on tall towers.

\subsubsection{Application of Wind Energy}

- Mechanical application: mainly (water pumping) multi blade windmill used for water pumping.

- Electricity generation: A wind turbine varies in size and types they are commercially available for electricity generation size of wind turbine ( 400 watt- $5 \mathrm{mw}$ ).

Also, wind is a form of solar energy. Wind is caused by the uneven heating of the atmosphere by the sun, the irregularities of the earth's surface, and rotation of the earth, wind flow pattern are modified by the earth's terrain, bodies of water, and vegetable cover. Thus, wind flow or motion energy when harvested by modern wind turbines, can be used to generate electricity.

\subsubsection{How Wind Power Is Generated}

The term 'wind energy' or 'wind power' describe be process by which the wind is used to generate mechanical power or electricity. Wind turbine converts the kinetic energy in the wind into mechanical power. This mechanical power can be used for specific tasks (such grinding grain or pumping water) or a generator can convert this mechanical power into electricity to power homes, business, schools etc. 
- Wind Turbines: wind turbines, like aircraft propeller blades turn in the moving air and power on electric generator that supplies an electric current simply stated, a wind turbine is the opposite of a fan, instead of using electricity to make wind like fan, wind turbine use wind to make electricity. The wind turns the blades which spin a shaft, which connect to a generator and makes electricity.

\subsubsection{Types ofWind Turbine}

Modern wind turbine falls into two basis groups

- Horizontal axis variety, like the traditional farm windmills used for pumping water and

- Vertical axis design, like the egg beater- style Darrieus mode, named after its French inventor. Most large,modern wind turbine are horizontal - axis turbines.

Turbine components

Horizontal turbine component includes

- Blade or rotor, which converts the energy in the wind to rotational shaft energy.

- A driven train, usually including a gear box and a generator.

- A tower that supports the rotor and drive train, and

- Other equipment and including controls, electrical cables, ground support equipment and interconnection equipment.

(Wind energy development programmatically Exclusive Information System) (E I S).

Renewable energy source is clean source of energy that have a much lower environment impact than conventional energy source such as coal, oil, nuclear and natural gas. They never run out while conventional source of energy is finite and will someday be used up. Most renewable energy source (solar, biomass, wind, and tidal wave) are derived from the sun, directly or indirectly, while others (geothermal and hydrogen) come from different sources other than the sun. For instance, the geothermal energy comes from the Earth's internal heat energy.

Wind energy resources are considered among the fastest growing energy resources all over the world, especially in the European Union, USA and Canada. Wind energy offers numerous advantages including clean fuel source that do not produce atmospheric pollutants that cause acidic rain or greenhouse gases. It is one of the lowest-priced atmospheric renewable technologies (Hussein, 2007). Generally, wind energy is a genuinely promising source of energy and it is one of the few green energy systems that have an everlasting nature. As a result, proper use of the resource through sustainable project designs would significantly contribute in solving the energy crisis that the world is faced (Manwellet al.,2002).

Wind turbines aremachines which transforms wind energy to mechanical energy. This in a generator is converted to electrical power. An integration of wind, wind turbine and aero generators is known as wind energy conversion systems (WECS) (Iheonu, 2002). One of the energies in the main aims of wind turbine generation system development is to continuously improve wind turbine efficiency. The speed of the wind turbine determined the efficiency of the conversion of the energy in the wind into mechanical energy, for a given wind speed, blades geometry and turbine orientation (Rubira\&McClloch, 2000).

Wind energy is one of the alternatives to fossil which clearly renew itself on a timely basis and is labeled as renewable energy. It is caused by convection of current in the air due to uneven heating of the earth's surface by the sun. The main wind over the earth arises from, cold air which comes from the polar region forcing the warm air over the tropics to rise. This wind energy can therefore be tapped and harnessed by wind turbine using the principle of conservation of energy with the abundance of sunshine in Gombe state, it is expected that this research will quantity the wind energy potential in semi-arid zone.

\subsection{Aim and Objectives}

This project is aimed at evaluatingthe wind energy potential in north eastern part of Nigeria, case study Gombe state.

Specific objectives of the study are to analyze the meteorological data based on statistical function for the distribution of energy and power densities.

\subsection{Scope and Limitation of the Study}

The scope of this study is aimed at analyzing possible meteorological data collected for four year (2007-2010) in Gombe state for the purpose of determining wind energy potential. This study is limited to only G0mbe state due to limitation of fund and time.

\subsection{Study Area and Justification}

Gombe is situation in north-east part of Nigeria within the latitude of $10^{0} 15^{\prime} \mathrm{N} 11^{0} 10^{\prime} \mathrm{E}$ and longitude $10.250^{\circ}$

$11.167^{\circ} \mathrm{E}$ the climate is tropical in Gombe. In harnmathan season there is much less rainfall in Gombe than in raining season. The average annual temperature is $25.5^{\circ} \mathrm{C}$ and annual rainfall average from $850 \mathrm{~mm}$ to $907 \mathrm{~mm}$ and the rainy season is usually from May to October.

The state, nicknamed 'the jewel of savannah' was created in October 1996 from part of old Bauchi state by General Sani Abacha's military government. It's location in the north eastern zone, right within expansive savannah; allow the state to share common borders with the state of Borno, Yobe, Taraba, Adamawa and Bauchi. The state has an area of $20,265 \mathrm{Km}^{2}$ and a population of around 2, 353,00 as of 2006 . 


\section{Literature Review}

Wind is the movement of air caused by pressure difference within the atmosphere. This pressure differences exert a force that causes air mass movement from a region of high pressure to region of low pressure. That movement of air is referred to as wind. Such pressure differences are caused primarily by uneven heating effects of the sun on the earth's surface. Thus, wind energy is form of solar energy (Breeze, 2009). It is the result of heating and cooling of the earth under the influence radiation coming turbulence and convection on the surface of the surface of the earth (Nikolaevet al., 2008)

Furthermore, wind being another form of energy created by the sum that is by heating of over atmosphere during the day and cooling at night. It is just like breathing; that is the earth breathes. The effect of wind near the surface of the earth are manifested by soil erosion, character of vegetation damage to structure and the production of waves on water surface. At higher level wind directly affects aircraft, missile and rockets operation, dispersion of industrial pollutants, radiation production of nuclear explosions, volcanic debris and other material. Directly or indirectly wind is responsible for the production of transport of clouds and precipitation and for the transport of cold and warm air masses from one region to another (Sanders \&Bluestrain, 2002).

\subsection{Historical Background}

History tells us that next to agriculture, it is very possible that wind might have been one of the first sources harnessed by man. Wind has been used to power machines capable of grinding corns, pumping water and producing electricity for hundreds of years. This technology probably has its origin in the ancient civilization of Asia as long as 200 B.C later on it was generally known all over Europe. The two most familiar types of wind machines are the traditional windmill used for grinding corn and the water pumping windmill usually provide water to farm and towns in the rural areas.

As the use of fossil fuels develop and the use of electricity generated from coal and oil became wide spread in the early $20^{\text {th }}$ century renewable began to contribute less and less to the world's energy needs. Research continued in many countries with advance being made both in theoretical and practical use of wind energy. Hence, the revival of the wider interest in wind power after 1970s did not start from scratch. But could build on a solid foundation of theories and practical experience when the new era of wind energy was initiated new materials and technologies were available. Composite materials such as fibred glass showed to be very strong and suitable for blades and electronics were developed to control the wind turbine, wind is now the world's fastest- growing energy source on percentage basis, with an installed generation capacity also increasing (www.nrel.gov/wind, 2005).

\subsection{Wind Power}

Power production from a wind turbine is proportional to the rotor disk area, and varies as the cube of wind speed. Doubling the diameter of the rotor leads to a four-time increase in power output. The influence of the wind is even more pronounced, with a doubling of wind speed leading to an eight-time in wind power. There have been considerable efforts to ensure that wind farms are developed in areas of the highest wind speeds and the turbines are optimally located. In some areas, very high towers are being used to take advantage of the increase of wind speed at high altitude in the outer edges of the atmospheric boundary layers (Tongchitpakdee, 2007)

Winds in general are stochastic and unpredictable frommoment to moment, its variability in velocity covers a wide range. Although the wind is not a completely reliable source of power from one day to the next, it is reliable source of energy power year by year. Another important characteristic of wind energy is its diffusivity that is its energy source is not concentrated. Its drag force on square meter of surface is small at low wind velocities, wind energy is a free raw material, but the equipment required for its power generation is not force and the wind power generation is complex. Originally, wind generation were built right to where their power was needed with the availability of long-distance electric power transmission, wind generator is now often on wind farms in windy location and huge one is being built offshore. Since they are renewable means of generating electricity, they are widely deployed. But their cost is often subsidized by governments either directly or indirectly through renewable credits.

The extent to which wind can be converted into useful work depends on

- The speed of the wind.

- The area of wind falling within span of the windmill rotator.

- The proportion of available of wind energy extracted by blade and

- The overall efficiency of the mechanical parts of the windmill itself

The power $(\mathrm{P})$ available in the wind increase as the cube of the wind speed (V) according the equation below

$\mathrm{P}=1 / 2 \rho \mathrm{AV}^{3} \ldots \ldots \ldots \ldots \ldots \ldots \ldots .2 .1$

Where $\rho$ is the wind density and $A$ is the cross-sectional area of the rotor and $V$ is the wind speed (Tongchitpakdee, 2007)

\subsection{Application of Wind Energy}

On the seas, wind has been used to propel ship and land it has served as variety of purposes the include

- Charging batteries for low energy device like lighting, radio,hifiTV etc.

- Supplying power to remote location such as caravan, boats out house workshop etc.

- Maintaining electricity for animal fencing, fish farming, irrigation chicken layer, meteorological recording station, radio repeater unit and may more

- Powering agriculture task such as grinding corn, sugar cane, thrashing, chalk cutting pumping fresh water for domestic livestock. 


\subsection{Benefits of Wind Power}

- The wind is free and with modern technology it can be captured efficiently. One the wind turbine is built the energy it produces does not cause greenhouse gases or other pollutants.

- Although wind turbines can be very tall each takes up only a small plot of land. This mean that the land below can still be used. This is especially the case in agricultural areas as farm can still continue.

- Many people find wind farm an interesting feature of the landscape.

- Wind turbines are available in a range of size which means vast range of people and business can them. Single households to small towns and villages can make good use of range of wind turbines available today.

\subsection{Limitation of Wind Power}

- The strength of the wind is not constant and it varies from zero to storm force. This means that wind turbine does not produce the since amount of electricity all the time there will be times when they produce no electricity at all.

- Many people feel that the country side should be left untouched, without these large structures being built. The landscape should be left in its natural form for everyone to enjoy.

- Wind turbinesare noisy. Each one can generate the same level of noise as a family car travelling at $70 \mathrm{mph}$.

- Technical expertise is needed to build the more sophisticated type of windmill.

\subsection{Theoretical of Study}

Wind has kinetic energy due to its motion and devices, such as wind turbine which is able to show it down can extract part of the energy and convert it to another form. Not all the energy can be extracted otherwise the wind would stop and no more air could pass research has shown that the energy available is the kinetic energy ( $E_{k}$ ) of the wind which is given as

$\mathrm{E}_{\mathrm{k}}=1 / 2 \mathrm{MV}_{\mathrm{f}} \mathrm{3}$

Where $\mathrm{M}$ is the mass of the air passing through volume $\mathrm{V}$ with the speed $\mathrm{V}_{\mathrm{f}}$ also known as free stream velocity (Ngala, 2004) since $M=\rho V$ where $\rho$ is the density of air therefore the volume of air passing through an area $A$ with speed $V_{f}$ at time $\mathrm{t}$ is. $A V_{\mathrm{f}} \mathrm{t}$.then $\mathrm{m}=\rho A \mathrm{~V}_{\mathrm{f}} \mathrm{t}$.

And $\quad E_{k}=1 / 2 \rho V_{f}^{3} t$

Power density is given by the derivatives of kinetic energy with respect to time

$\mathrm{P}_{\mathrm{d}}=\frac{d E}{d t}=1 / 2 \rho \mathrm{AV}_{\mathrm{f}}{ }^{3}$.

Where $A=2 \pi r^{2}$ and $r$ is the radius of the blade

$\mathrm{P}_{\mathrm{d}}=\rho \pi \mathrm{r}^{2} \mathrm{~V}_{\mathrm{f}}{ }^{3}$.....

To obtain the power extractable from the wind, we assume that rotor is replace by disc containing many blades which produce uniform change of velocity of air passing through it, let the velocity of air acting on the rotor be $V_{r}$ and the velocity of air leaving be $V_{w}$ that is the wave velocity. Average axial velocity at the disc is given as

$\mathrm{V}_{\mathrm{r}}=1 / 2\left(\mathrm{~V}_{\mathrm{f}}+\mathrm{V}_{\mathrm{w}}\right)$

The power output is given as

$\mathrm{P}_{\mathrm{o}}=1 / 2 \rho A \mathrm{~V}_{\mathrm{r}}\left(\mathrm{V}_{\mathrm{f}}^{2}-\mathrm{V}_{\mathrm{w}}^{2}\right)$

But the velocity of the wind acting on the rotor is less than input velocity

$\mathrm{V}_{\mathrm{r}}=\mathrm{V}_{\mathrm{r}}(1-\mathrm{a})$.

Where ' $a$ ' is the axial interference factor, and hence

$\mathrm{V}_{\mathrm{w}}=\mathrm{V}_{\mathrm{f}}(1-2 \mathrm{a})$

Substituting $V_{r}$ and $V_{w}$ from equation (2.6) and (2.7) into equation (2.5)

$P_{0}=1 / 2 \rho A V_{f}^{3}(1-a)^{2} .4 a$

$\mathrm{P}_{\mathrm{o}}=4 \rho \pi \mathrm{r}^{2} \mathrm{~V}_{\mathrm{f}}^{3} \mathrm{a}(1-\mathrm{a})$

The maximum power output is obtained by equating the first derivatives $\frac{P o}{d a}$ to zero

$\mathrm{P}_{\max }=\frac{d p o}{d p}=0$

And it gives ' $a$ ’ = $1 / 3$

Substitute the value of ' $a$ ' into equation (2.9) gives

$P_{\max }=\frac{16}{17} \rho \pi r^{2} \mathrm{Vr} 3$

Therefore the maximum theoretical efficiency should be $\eta=\frac{P \max }{P d}=\frac{16}{17}=0.593$

The coefficient 0.593 is referred as the Betz's limits, and this signifies that efficiency of wind turbines can never be more than 60\% no matter the improvement (http//:www.goggle.com 2005)

\subsection{Measurement of Wind Energy}

Wind measurement has to do with determination of these parameters these are; the size of an air samples its speed and direction of motion. Air movement or wind is a vector quantity that is specified by speed and direction. Anemometer measure wind speed and wind vanes indicate direction, while the size of the air has to do with the area of the land which it covers; there are many types of wind of measuring instrument. These are research wind instruments typically measure both horizontal and vertical air movement while operational and personal wind sensors measure only 
the horizontal component. Due to advances in technology, we now have remote wind sensor which can make measurement without contact with the portion atmosphere measured (Walter, 2002).

\subsection{The Beafort Scale}

0ne of the first scale to estimate wind speed and the affect was created by Britain's Admiral, sir Francis Beaufort (1774-1857). He developed the scale in 1805 to help sailor estimate the wind via visual observation. The scale starts from zero to a force of 12 . The Beaufort scale is still scale is still used today to estimate wind strengths.

\begin{tabular}{|c|c|c|c|}
\hline $\begin{array}{l}\text { Beaufort } \\
\text { Free }\end{array}$ & Description & Effect on Land & Speed (knots) \\
\hline 0 & Calm & Smokes rises vertically & Less than 1 \\
\hline 1 & Light air & $\begin{array}{l}\text { Direction of wind shown by smoke drift, but not by } \\
\text { wind varies. }\end{array}$ & $1-3$ \\
\hline 2 & Light breeze & $\begin{array}{l}\text { Wind felt on face: leaves rustle ordinary vanes moves } \\
\text { by wind }\end{array}$ & $4-6$ \\
\hline 3 & Gentle breeze & $\begin{array}{l}\text { Leaves and small twigs in constant motion: wind } \\
\text { extends light flag }\end{array}$ & $7-10$ \\
\hline 4 & $\begin{array}{l}\text { Moderate } \\
\text { breeze }\end{array}$ & Raise dust and loose paper: small branches are moved & $11-16$ \\
\hline 5 & Fresh breeze & $\begin{array}{l}\text { Whole trees in leaf begin to swag: crested wavelets } \\
\text { form on in land waters }\end{array}$ & $17-21$ \\
\hline 6 & Strong breeze & $\begin{array}{l}\text { Large branches in motion: whistling heard in telegraph } \\
\text { wires; umbrella used with difficulty }\end{array}$ & $22-27$ \\
\hline 7 & Near gale & $\begin{array}{l}\text { Whole trees in motion; inconvenience felt when } \\
\text { walking against the wind }\end{array}$ & $28-33$ \\
\hline 8 & Gale & Break twigs of trees; generally, impedes progress & $34-40$ \\
\hline 9 & Strong gale & Slight structure damage occurs & $41-47$ \\
\hline 10 & Storm & $\begin{array}{l}\text { Seldom experienced in land; trees up rooted } \\
\text { considerable structure damage occurs }\end{array}$ & $48-55$ \\
\hline 11 & Violet storm & $\begin{array}{l}\text { Very rarely experienced; accompanied by wide speed } \\
\text { damage }\end{array}$ & $56-63$ \\
\hline 12 & Hurricane & Whole hangers disappear & 64 \\
\hline
\end{tabular}

Table 1: The Beaufort Scale

Source: Http//.www.Google.com. 2005

\subsection{Wind Rose}

A wind rose is a graph tool used by meteorologist to give a succinct view of how wind speed and direction are typically distributed at particular location. Historically, wind roses were predecessor of the compass rose (found on maps) as there was no differentiation between a cardinal direction using a polar coordinate system of gridding, the frequency of winds over a time period is plotted by wind direction with color band showing wind speed ranges the direction of the longest spoke shows the wind direction with the greatest frequency.

\subsection{Wind Energy Development in Nigeria}

Ojosu and Salawa in 1990 carried out a research on wind energy development in Nigeria and the following was revealed.

- The first major feasibility study was done in 1984 for Northern Nigeria by the united Nation Development Programme (UNDP). It attempted to analyze the wind energy potential of this country.

- The objective of the project is to demonstrate, test the technology and local condition, to determine the technical feasibility, economic viability and social acceptability of the wind machine.

- Their reports cover five towns Kaduna, Kano, Ilorin, Sokoto and Maiduguri.

- Alternatives are compared for Nigeria based on the data from Sokoto water development and it shown that wind pumps offer lower cost than diesel pump

- In June 1989, tractor and equipment ( $\mathrm{T}$ and $\mathrm{E}$ ) started making wind pump in Nigeria, though they carried out a feasibility study using data from the Nigeria meteorological station Oshodi near Lagos, as result of which engineers were sent for the training on windmill in U S A

- In conclusion, OJosu and Salawu (1990) stressed that basic and applied research should be interstitial toward determining the wind characteristics country wide. That it calls for support from the appropriate government organs like the Agriculture Development Project (A.D.P), water resource development and energy commission of Nigeria.

\subsection{Wind Machines}

A wind machines takes energy from the wind (fluid) to produce power. This wind is called windmill or wind turbines the wind is energy, because it is moving, is in form of kinetic energy and it all the energy were captured by the 
propeller or rotor there would be no flow of air, therefore the "lost" energy is what keep the air flowing the maximum theoretical power is $16 / 17$ of the wind's power (from eqn. 2.13) which is known as the Betz limit but the maximum practical power is less than that power is less the that power available is given by

$\mathrm{P}_{\max }=\frac{16}{17} \pi \mathrm{r}^{2} \rho \mathrm{V}_{\mathrm{f}}{ }^{3}$.

It can be seen that by doubling the velocity of the wind, the available power is increased eight times $(2 \times 2 \times 2)$ and by doubling the blade diameter the available power is increased four times (2x2). For all practical purposes wind speed below $3 \mathrm{~ms}^{-1}$ provide little or no usable energy, even though the blades may be spinning (http//www.goggle.com.2005)

Wind turbines must have short at the wind to perform efficiently. Turbulence, which both reduces performance and "work" the turbine harder than smooth air is highest close to the group and diminishes with height, also wind speed increase with height above the ground. As a general rule of thumb, you should install a wind turbine on a tower such that it is at least $30 \mathrm{ft}$ above any obstacles.

\subsection{Types of Windmills}

Windmills can be divided two major type horizontal axis and vertical axis machines.

- Horizontal machine sometimes known as HAWT (horizontal Axis Wind Turbine) are the traditional conventional design, they consist of rotor with one to twenty blades driving a generator or a pump either directly or through gear box, chain or belt system. A tail name or fantail is required direct the machine into the wind, they are usually more efficient than vertical axis machines.

- Vertical machines also known as VAWT (Vertical Axis Wind turbines) Savanius and Darius are two design of vertical axis machines. This type of unit is often not situated on a tower and does not have to be directed into the wind material and constructions are usually cheaper than horizontal axis.

Other types ofwindmills include $\mathrm{H}$ shape vertical axis machine, unorthodox wind mill etc.

\subsection{Generators}

To make an electricity, an electrical generator is required the first wind generator used a dynamo. These have now been replaced with alternators can be used however they are designed to run at high speed and are therefore not normally suitable without gearing or modification.

Standard alternator uses electric field that use power typically around ten permanent magnet alternator this particularly true at low speeds. Although permanent magnet alternator is far more suited to the generation of electricity using wind power, they are very expensive.

\subsection{Energy Storage}

\subsubsection{Batteries}

Because somebody may not to always use electricity produced by a wind generator immediately, a form of storage is usually required, the most readily available is the lead acid battery on cars, lorries, boats etc. sealed or maintenance free batteries are the best lead acid battery and give up to eight years of life. All batteries are very expensive, but sometimes using second hard batteries can reduce this cost. Car batteries can be destroyed if not maintained carefully lead acid batteries are the most cost effective, although other types such as nickel-cadmium are available.

\subsubsection{Hot Water}

Another method of storing the energy produced a windmill is by using it to heat water. Hot water is a very usable form of storage the amount energy lost over times being dependent on the insulation around the tank. This method of storage is best suited to large wind changes since it is most likely that the limited amount of energy produced by smaller unit would be batter utilized in the form electricity for other purposes.

A wind powered immersion heater does not have to be the only means of heating the water. It can be used in conjunction with an existing immersion heater supplied by the means of adapting or purchasing a new water tank to take the additional heater.

\section{Material and Method}

\subsection{Materials}

The materials used for this study are data for wind speed (Table 2) these data were obtained from the department of meteorological service, Upper Benue River Basin Development authority, DadinKowaGombe, Gombe state. For four years (2007-2010). The wind speed obtained were in $\mathrm{km} /$ day and is then converted to S I unit give $10 \mathrm{~m}$ above sea level (Ngala, 2004). This measuring instrument is located at the weather station DadinKowaGombe state.

Other auxiliary data materials collected are maximum and minimum temperature and average air density (1.124 $\mathrm{kgm}^{-2}$ ) for Gombe state the data for wind speed. Are shown in Table 2 and 3 respectively 


\begin{tabular}{|c|c|c|c|c|c|c|c|c|c|c|c|c|}
\hline Years & Jan & Feb & Mar & Apr & May & Jun & Jul & Aug & Sep & Oct & Nov & Dec \\
\hline 2007 & 2.00 & 3.20 & 1.80 & 3.90 & 6.05 & 7.89 & 6.27 & 4.67 & 1.99 & 1.75 & 2.67 & 2.04 \\
\hline 2008 & 2.83 & 4.54 & 6.50 & 4.25 & 7.20 & 5.12 & 6.56 & 5.25 & 4.29 & 2.56 & 1.87 & 0.97 \\
\hline 2009 & 1.96 & 4.52 & 1.87 & 6.67 & 5.67 & 6.55 & 5.84 & 4.58 & 4.00 & 3.97 & 2.90 & 3.10 \\
\hline 2010 & 1.75 & 0.63 & 3.42 & 6.11 & 5.40 & 5.02 & 4.40 & 4.37 & 3.18 & 3.62 & 1.82 & 2.79 \\
\hline
\end{tabular}

Table 2: Mean Monthly Wind Speed (M/S) at 10m High (From 2007 to 2010)

\begin{tabular}{|c|c|c|c|c|}
\hline Months & $\begin{array}{c}\text { Mean Monthly } \\
\text { Wind Speed m/s }\end{array}$ & $\begin{array}{c}\text { Power Density } \\
\text { Per Area w/m }\end{array}$ & $\begin{array}{c}\text { Percentage Wind } \\
\text { Speed \% }\end{array}$ & $\begin{array}{c}\text { Percentage Power } \\
\text { Density } \%\end{array}$ \\
\hline Jan & 2.14 & 5.50 & 4.50 & 0.92 \\
\hline Feb & 3.22 & 18.76 & 6.77 & 3.13 \\
\hline Mar & 6.08 & 22.08 & 7.14 & 3.68 \\
\hline Apr & 5.23 & 80.40 & 10.99 & 21.04 \\
\hline May & 6.08 & 126.31 & 12.77 & 21.78 \\
\hline Jun & 6.15 & 130.73 & 12.92 & 17.78 \\
\hline Jul & 5.77 & 107.96 & 12.12 & 9.85 \\
\hline Aug & 4.72 & 59.10 & 9.92 & 3.58 \\
\hline Sep & 3.37 & 21.51 & 7.08 & 2.48 \\
\hline Oct & 2.98 & 14.87 & 6.26 & 1.17 \\
\hline Nov & 2.32 & 7.01 & 4.87 & 1.00 \\
\hline Dec & 2.21 & 6.07 & 4.66 & $100 \%$ \\
\hline$\sum$ & 47.59 & 600.3 & $100 \%$ & \\
\hline
\end{tabular}

Table 3: Mean Monthly Wind Speed, Power Density and Their Mean Months Percentages

1. Determination of power density

$P_{d}=1 / 2 \rho A V_{f}^{3}=w$

$\frac{P d}{A}=1 / 2 \rho V_{\mathrm{f}}^{3}$

Where $\mathrm{P}_{\mathrm{d}}=$ power density, $\rho=$ density of wind, $\mathrm{A}=$ area of blade and $\mathrm{V}=$ wind speed

$\frac{P d}{A}=0.5 \times 1.124 \times(2.14)^{3}$

$\approx 5.50 \mathrm{w} / \mathrm{m}^{2}$

2. Determination percentage wind speed

$\frac{2.14}{47.59} \times 100=4.50$

3. Determination percentage power density

$\frac{5.50}{600.3} \times 100=0.92$

\subsection{Method of Data Collection}

Mechanical cup anemometer was used to measure wind run or wind speed. The data was collected daily by the meteorological technician in DadinKowa Upper Benue Basin Development Authority maximum and minimum temperature were measured using maximum thermometer of mercury in-glass and minimum thermometer of alcohol in glass respectively.

\subsection{Method of Data Analysis}

In the analysis of the data for wind speed maximum and minimum temperatures, statistical method was employed as fallows

- Regression and correlation

- Percentage distribution

- Graphical methods

\subsubsection{Regression and Correlation}

Regression analysis: This enables us to study the linear relationship between a pair ofvariables. Thus, one variable is a function (dependent) of the other shown below.

$\mathrm{Y}=\alpha+\beta \mathrm{x} \ldots \ldots \ldots \ldots \ldots \ldots \ldots \ldots \ldots \ldots \ldots \ldots \ldots \ldots \ldots \ldots \ldots \ldots \ldots$

Where $\alpha$ and $\beta$ are constants and can be evaluated by least square method. The equation above is an equation of a straight line with slope $\beta$ and intercept $\alpha$. The dependent variable $Y$ is representing wind speed while the independent variable $X$ is representing the difference between maximum and minimum temperature. The constants $\alpha$ and $\beta$ can be obtained by the following expressions.

$\alpha=\frac{\left(\sum y\right)\left(\sum x^{2}\right)-\left(\sum x\right)\left(\sum x y\right)}{n\left(\sum x^{2}\right)-\left(\sum x\right)^{2}}$

$\beta=\frac{n\left(\sum x y\right)-\left(\sum x\right)\left(\sum y\right)}{n\left(\sum x^{2}\right)-\left(\sum x\right)^{2}}$

Where $\sum$ summation and $\mathrm{n}=$ total number of the variation. 
Correlation Analysis: if two quantities very in such a way that change in one quantity results change in other quantity. These quantities are said to be correlated the coefficient of linear correlation also known as the strength of the indication is given by

$\gamma=\frac{n\left(\sum x y\right)-\left(\sum x\right)\left(\sum y\right)}{\sqrt{\left[n\left(\sum x^{2}\right)-\left(\sum x\right)^{2}\right]\left[n\left(\left(\sum y^{2}\right)-\left(\sum y\right)^{2}\right]\right.}}$

Where $r$ is the coefficient of linear correlation which varies +1 and -1 corresponding to perfect positive correlation and perfect negative correlation respectively, the quantity $\mathrm{r}^{2} \times 100 \%$ is the amount of variable in the value of the variable $\mathrm{Y}$ which is accounted for by the linear relationship with variable (Dibal, 2001)

\subsection{Height Correlation Exponential for Various Terrain}

$\mathrm{V}_{2}=\mathrm{V}_{1}\left[\frac{h 2}{h 1}\right] \mathrm{k}$

The wind speed profile curves can be used to find the wind speed available at particular height in a given below.

The $V_{1}$ is the average wind speed at a reference height $h_{1}$ and $V_{1}$ is the unknown average wind speed at some new height. Hence the above formula can be used to find the wind speed of Gombe state at $10 \mathrm{~m}$ with reference height of 2.5 and $\mathrm{K}$ is the height correlation exponential which can be of obtained from table below.

\begin{tabular}{|c|c|}
\hline Roughness Characteristics & Height Correction Exponent K \\
\hline Smooth surface, ocean and sand & 0.14 \\
\hline Low grass or low crops & 0.16 \\
\hline Tall row crops or low woods & 0.21 \\
\hline High grass or low crops & 0.28 \\
\hline High woods and tall trees & 0.28 \\
\hline Suburbs and cities & 0.4 \\
\hline
\end{tabular}

Table 4: Height Correction Exponential For Various Terrains.

Source: Stout, 1990

\section{Results and Discussion}

Result of analysis data in 3.1 and 3.2 are presented accordingly.

\subsection{Results}

\begin{tabular}{|c|c|c|}
\hline Year & Mean Annual Wind Speed (m/s) & Power Density Per Unit Area w/m $\mathbf{m}^{\mathbf{2}}$ \\
\hline 2007 & 3.69 & 28.24 \\
\hline 2008 & 4.33 & 45.62 \\
\hline 2009 & 4.30 & 44.68 \\
\hline 2010 & 3.54 & 24.93 \\
\hline
\end{tabular}

Table 5: Mean Annual Wind Speed and Power Density Per Unit Area

In order to study the linear relationship between maximum and minimum temperature regression and correlation analysis were used maximum and minimum temperature difference correlation with speed the least square method is in table.

\begin{tabular}{|c|c|c|c|}
\hline Months & Maximum Temp ${ }^{\circ} \mathbf{C}$ & Minimum Temp ${ }^{\circ} \mathbf{c}$ & Temp Difference $^{\circ} \mathbf{c}^{-1}$ \\
\hline January & 33.50 & 15.25 & 18.25 \\
\hline February & 34.75 & 19.25 & 15.50 \\
\hline March & 36.75 & 22.50 & 14.25 \\
\hline April & 39.25 & 26.50 & 12.75 \\
\hline May & 38.00 & 27.50 & 11.50 \\
\hline June & 36.00 & 24.50 & 8.00 \\
\hline July & 32.50 & 24.50 & 7.00 \\
\hline August & 30.50 & 23.50 & 8.50 \\
\hline September & 32.50 & 24.00 & 10.75 \\
\hline October & 34.50 & 23.75 & 17.75 \\
\hline November & 36.25 & 18.50 & 19.00 \\
\hline December & 36.00 & 17.00 & \\
\hline
\end{tabular}

Table 6: Mean Annual Temperature Difference 


\begin{tabular}{|c|c|c|c|c|c|}
\hline Months & $\begin{array}{c}\text { Difference in } \\
\text { Temp }^{\circ} \mathbf{c} \mathbf{x}\end{array}$ & $\begin{array}{c}\text { Wind Speed } \\
(\mathbf{m} / \mathbf{s}) \mathbf{y}\end{array}$ & $\mathbf{x}^{\mathbf{2}}$ & $\mathbf{y}^{\mathbf{2}}$ & $\mathbf{X Y}$ \\
\hline January & 18.25 & 2.14 & 333.06 & 4.58 & 39.06 \\
\hline February & 15.50 & 3.22 & 240.25 & 10.37 & 49.91 \\
\hline March & 14.25 & 3.40 & 203.06 & 11.56 & 48.45 \\
\hline April & 12.75 & 5.23 & 162.56 & 27.35 & 66.68 \\
\hline May & 10.50 & 6.08 & 110.25 & 36.97 & 63.84 \\
\hline June & 11.50 & 6.15 & 132.25 & 37.82 & 70.73 \\
\hline July & 8.00 & 5.77 & 64.00 & 33.29 & 46.16 \\
\hline August & 7.00 & 4.72 & 49.00 & 22.28 & 33.04 \\
\hline September & 8.00 & 3.37 & 72.25 & 11.36 & 28.65 \\
\hline October & 10.75 & 2.98 & 115.56 & 8.89 & 32.04 \\
\hline November & 17.75 & 2.32 & 315.06 & 5.38 & 41.18 \\
\hline December & 19.00 & 2.21 & 361.00 & 4.88 & 41.99 \\
\hline$\sum$ & $\sum=153.75$ & $\sum=47.59$ & $\sum=215.30$ & $\sum=214.73$ & $\sum=561.73$ \\
\hline
\end{tabular}

Table 7: Monthly Mean Wind Speed Power Density, Percentage Power Density and in Difference in Temperature

Mean monthly wind speed $=\frac{\sum y}{n}$

$\frac{47.59}{12}=3.97 \mathrm{~m} / \mathrm{s}$

Monthly power density $\frac{600.3}{12}=50.03 \mathrm{Wm}^{-2}$

Mean monthly difference between maximum and minimum temperature $=\frac{\sum x}{n}$

$\frac{153.75}{12}=12.81^{\circ} \mathrm{C}$

From equation (3.1), (3.2) and (3.3) we have $Y=\alpha+\beta x$

Where $\alpha=\frac{\left(\sum y\right)\left(\sum x^{2}\right)-\left(\sum x\right)\left(\sum x y\right)}{n\left(\sum x^{2}\right)-\left(\sum x\right)^{2}}=0.02$

And $\beta=\frac{n\left(\sum x y\right)-\left(\sum x\right)\left(\sum y\right)}{n\left(\sum x^{2}\right)-\left(\sum x\right)^{2}}=1.2 \times 10^{-4}$

Hence the equation joining the wind speed and difference between maximum and minimum temperature given by the expression.

Wind speed as the function of temperature is thus;

$\gamma=\frac{n\left(\sum x y\right)-\left(\sum x\right)\left(\sum y\right)}{\sqrt{\left[n\left(\sum x^{2}\right)-\left(\sum x\right)^{2}\right]\left[n\left(\left(\sum y^{2}\right)-\left(\sum y\right)^{2}\right]\right.}}=0.68$

$\gamma^{2} \times 100=46.24 \%$

The graphical analysis and percentage distribution of power density are in fig 4.1 and 4.3respectively.

Based on eqn. 4.1 a linear plot of wind speed (y) against difference in temperature (x) is presented in fig 4.3 the standard error of regression line of wind speed and difference in temperature.

$S_{y x}=\sqrt{\frac{\sum y^{2}-0.2 \sum y-1.2 \times 10^{-4} \sum x y}{n}}=4.13$

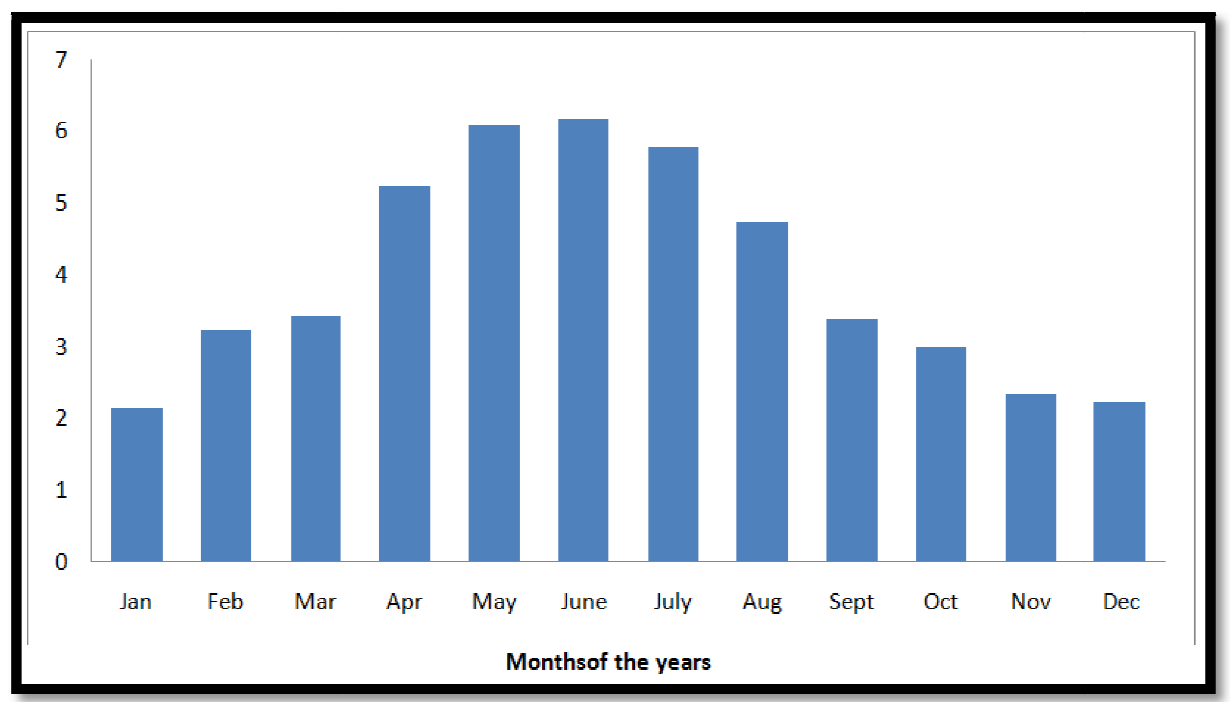

Figure 1: Wind Speed M/S against Months Bar Chart Graph 


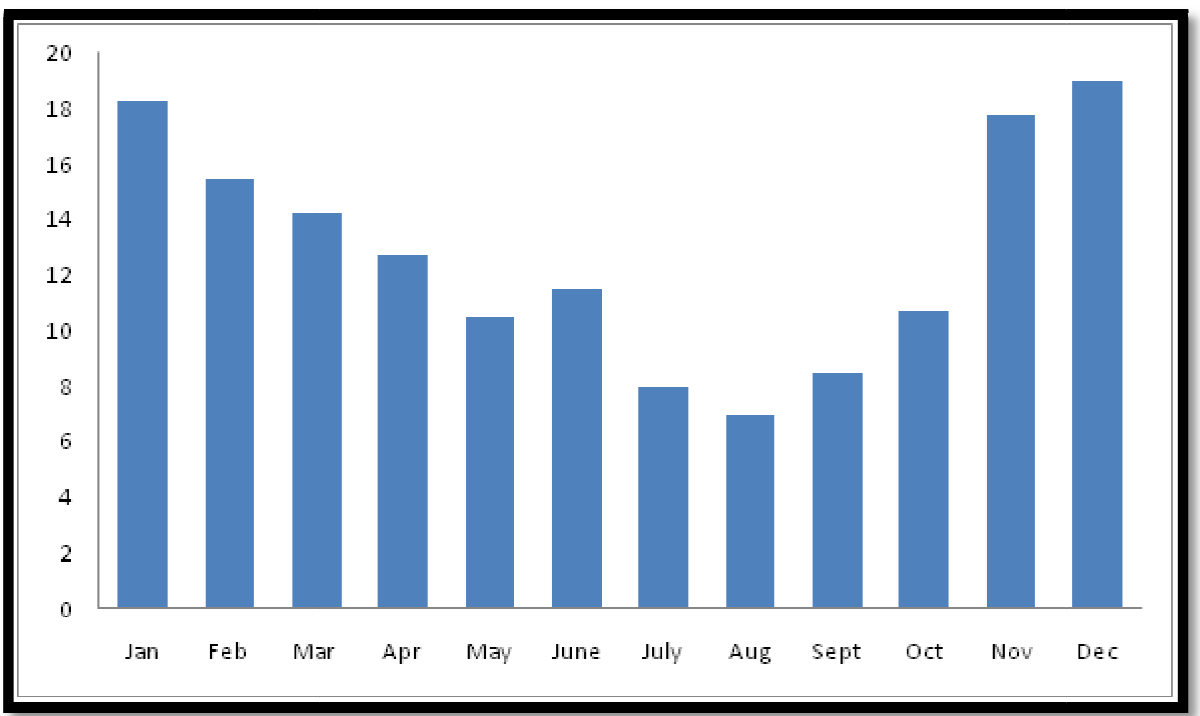

Figure 2: Temperature ${ }^{\circ} \mathrm{C}$ bar Chart Graph

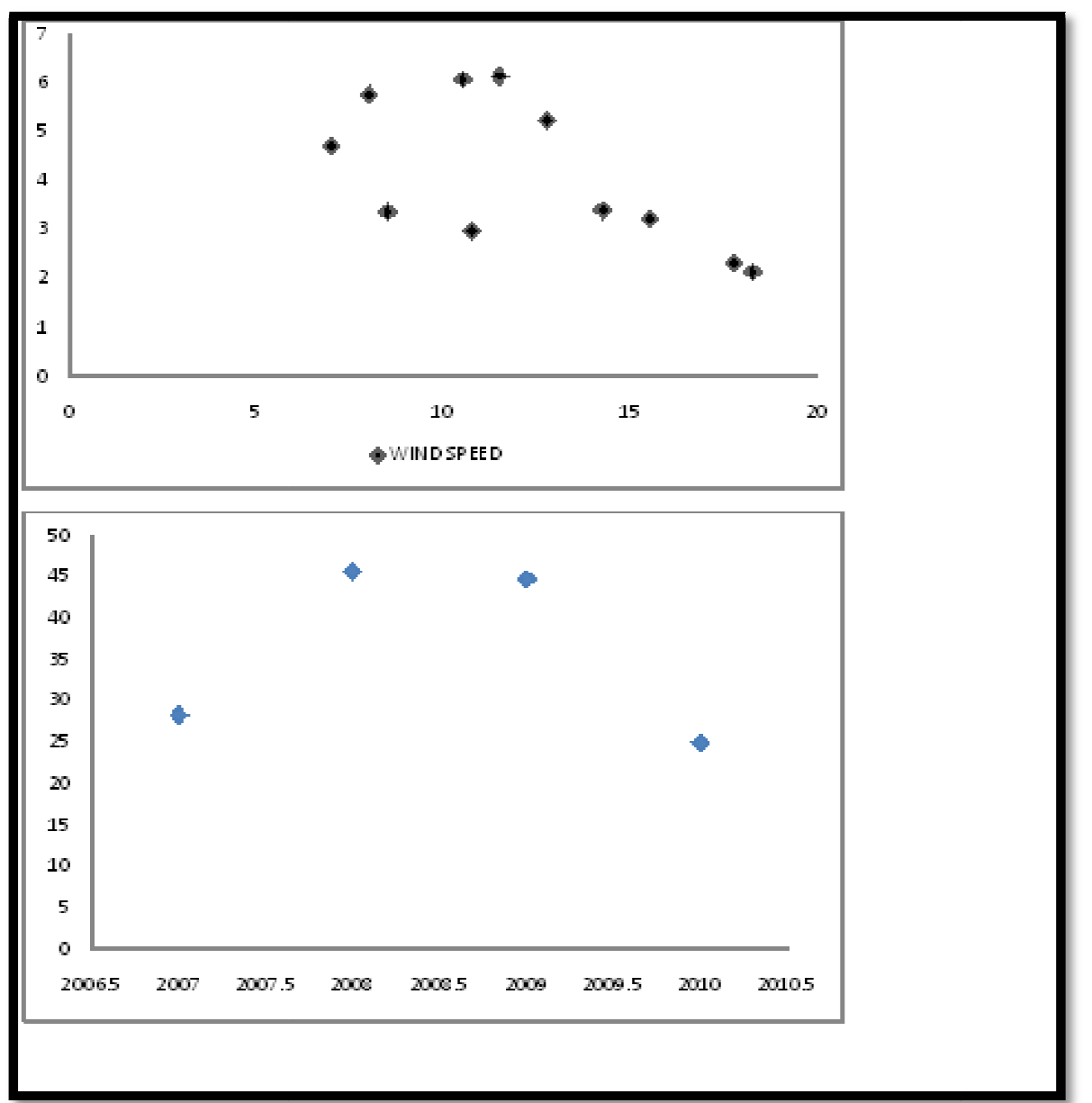

Figure 3: Wind Speed M/S against Temperature ${ }^{\circ} \mathrm{C}$

\subsection{Discussion}

The annual wind speed for four years (2007-2010) with corresponding power density was analyzed. The analysis (fig 4.1) shows that the power density which is the kinetic energy per unit area has fluctuating pattern with a peak in 2008 (approximately $45.62 \mathrm{w} / \mathrm{m}^{2}$ ) and it least value in 2010 (approximately $24.93 \mathrm{w} / \mathrm{m}^{2}$ )

The mean monthly wind speed obtained for this region is $3.96 \mathrm{~m} / \mathrm{s}$ which is within the threshold for which wind turbine can generated power of up to $69.51 \%$ per annum. The variation of wind speed in this region have been grouped into three- month seasonal period in conformity withIheonu and Akingbade (2002)

- Winter solstice (November- January)

- Verna equinox (February - April)

- Summer solstice (may-July) and

- Autumnal equinox (August- October). 
The winter solstice period represents the harmattan seasonwhen cool and dust laden North- East trade wind from the semi-arid zone heavily over cast within cloud- free weather condition. The Verna Equinox is the actual dried season in the semi-arid region of Nigeria while the summer solstice represents the period in which the rainy season set in and wind speed reaches its peak in this period. Autumnal Equinox period is generally classified as a wet season and is also characterized by low wind speed.

A correlation test was conducted to conform if there is any linear relationship between maximum and minimum temperature and from equation 4.1 it implies that there is a positives correlation between these meteorological parameters a standard error of 4.13

\section{Summary, Conclusion and Recommendation}

\subsection{Summary}

The study was conducted to describe the comparison between measured temperature and wind speed which were obtained from DadinKowa meteorological department. As observed from the result and discussion part, average measured wind power, wind speed and temperature difference maximum value were in May, June and July whereas the minimum valuedregistered wereNovember and December months.

\subsection{Conclusion}

In this, we have discovered that the fluctuating pattern of the power density of the wind speed is due to kinetic energy of the moving atmospheric air which blows the North-East trade wind from the Sahara Desert through the semiArid zone of Nigeria.

Also, we have understood that the correlation between wind speed and difference between the maximum and minimum temperature is positive hence we conclude that wind speed increases when difference between maximum and minimum temperature increases and vice-versa.

The effective percentage of Annual power density of $46.24 \%$ can give us power density of up to $50.03 \mathrm{w} / \mathrm{m}^{2}$ and this is large enough to serve as power supply even though due to its stochastic nature it may not provide continuous steady power. This plays an important role in the energy policy of Nigeria since it has the ability to save power (Energy Conservation) and it also be operated either alternatively or in parallel with diesel engine to reduce fuel consumption. Furthermore, power source from wind energy is a renewable energy and pollution free environmentally friendly.

\subsection{Recommendation}

Currently, wind energy is another alternative source that Gombe state is engaged in. it is promising at its current status since its efficiency is close to the conventional energy source. However, since this study focused only on data of four years it is difficult to tell about the change in the performance of the turbines with time. Hence, more follow-up study is required to get a better picture about the performance of this wind farm project.

\section{References}

i. Dibal, P.N. (2001). Undergraduate Reading Material for Statistics, University of Maiduguri.(Unpublished)

ii. El-Buba, S.S. (2004). Lecture Notes Geography Department, University of Maiduguri, Nigeria.

iii. Hussein,T.(2007). Wind Farms Production, Control and Prediction.Ph.D dissertation. University of waterloo.

iv. Iheonu, E. E., Akingbade, F. O., \&Ocholi,M. (2002). Wind Resource Variation over Selected Sites in West AfricanSubRegion. Nigeria J. Renewable Energy, 10, 43-47

v. Maxwell, J. F., McGowan, J .G. \& Rogers, A. L.(2002). Wind Energy Explained: Theory, Design and Application. John Wiley and Sons, New York.

vi. Ngala, G.M.\&Liman, B.S. (2004) Assessment of Wind Energy Potential of Borno State. Journal of Life and Environment Science.

vii. Nikoleav, V.G., Ganaga, S.V., \&Kudryashov, Y. (2008). National Cadastre Wind Energy Research \& Development Authority. Retrived March 4, 2013, from www.powernaturally.org.

viii. Ojoau, J.O.\&Salawa R, I. (1990). Wind Energy Development in Nigeria.

ix. NigeriaJournal of Solar Energy, 9, 209-222

X. Rubira, S.D. \&McCulloch,M.D.(2000). Control Method And Comparison of Doubly Fed Wind Generators Connected To Asymmetric Transmission Lines,IEEE Trans. Industry Applications, vol.36( 5), 986-991.

xi. Sanders, F (2002): Wind Rose. McGraw-Hill Encyclopedia of Science and Technology. Washington D.C Vol.19 P 561 and 562.

xii. Sanders, F.\&Bluestein (2002). Wind Energy. Mcgraw-Hill, Encyclopedia of Science and Technology. Washington D.C Vol. 19.P554.

xiii. Stembridge, J.H. \& Myers, J. (1975).Region And People of The World Oxford Progressive Geography, Senior Series, Revised andKetric Edition. Oxford University Press London.P 27.

xiv. Stout, B.A. (1987).Handbook of World Agriculture. London: El-Sevier Science Publication. P 59

xv. Tongchitpakdee, C. (2007). Computational Studies of The Effects of Active and A Passive Circulation Enhancement Concepts on Wind Turbine Performance. Mscthesis. Geogia Institute of Technology.

xvi. Walter, F.D. (2002).Wind Measurement. Mcgraw Hill, Encyclopedia of Science and Echnology, Washington D.C Vol.19 P561.

xvii. Website (2005). http//www.google.comhttp//www.nret.gov./wind/. 